\title{
Advertising, consumer behaviour and health: Exploring possibilities for health promotion
}

Received: 14th June, 2002

\section{Bob M. Fennis}

obtained his PhD from Utrecht University, The Netherlands (1999). He is currently assistant professor of Marketing Communications at the Free University, Amsterdam. His research interests include the impact of health-related advertising on consumer attitudes and behaviour and the dynamics of corporate communications. In addition, he regularly acts as a consultant on communication issues for various profit and non-profit organisations.

\section{Keywords consumer behaviour, health promotion, television advertising}

\begin{abstract}
The present paper examines the potential of a consumer behaviour approach as a means of using television advertising for health-promotion purposes. Research on the portrayal of health on television is reviewed and recent developments in employing regular television broadcasting for health education are discussed. Based on empirical findings, a consumer behaviour approach for health promotion is outlined, based on the relationship between health behaviour and consumer behaviour as an outcome of targeted advertising. The theoretical and practical implications of this approach are discussed.
\end{abstract}

Bob Fennis

Department of Public Administration and

Communication Sciences DBL 859, Free University,

De Boelelaan 1081c,

1081 HV Amsterdam,

The Netherlands.

Tel: + 31204446911 ;

Fax: + 31204446820 ;

e-mail: bm.fennis@scw.vu.nl

\section{INTRODUCTION}

Can television advertising be used for health-promotion purposes? This question may desperately require an answer since modern mass media in general and television in particular constitute an important source of health information for consumers. ${ }^{1,2}$ Indeed, research conducted in the USA has indicated that, after doctors and dentists, television is a prime source of health information ${ }^{3}$ and this prominent ranking of television as a source of health information has recently been replicated. ${ }^{4}$

Over the last two decades, the interest of public health organisations in employing television as a means of health promotion and disease prevention has increased. ${ }^{5,6}$ In part, this emerging interest can be explained by the realisation that many of the illnesses and diseases that plague modern Western societies are intrinsically linked to lifestyle factors. Illnesses such as AIDS, strokes, or cardiovascular disease are to a large extent assumed to be the consequence of an unhealthy lifestyle and, thus, disease risk should be markedly reduced by changing certain lifestyle-related behaviours. ${ }^{7}$ Mass media in general, and television in particular, were thought to be able to contribute a great deal to these behavioural changes. Public health campaigns employing television have, however, generally not been very successful in modifying consumer behaviour. ${ }^{8}$ In this respect, Donohew ${ }^{9}$ has summarised the history of public health campaigns as 'a story of expensive failures'.

One of the key reasons for this lack of success may be found in an insufficient realisation on the part of public health communication professionals that campaign messages do not operate in a 
vacuum but are surrounded by an 'information environment' that communicates health-related information in its own right, and hence may promote or hinder the effectiveness of campaigns. ${ }^{10,11}$ This paper will focus on an important part of this information environment on television: commercial advertising. Gerbner et al. ${ }^{12}$ have noted that health not only has a dramatic and a social function on television, but also an important sales function. More and more, health claims are used in commercials to promote products, ${ }^{13}$ and more healthrelated products are entering the market than ever, probably as a result of increased health awareness among consumers. Health has become a core value in modern Western society, ${ }^{14,15}$ and advertising apparently reflects this orientation. This presents a vast potential for advertising to influence health-related attitudes and behaviour. ${ }^{16}$ Empirical support for this contention has been demonstrated in an experimental study by Goldberg et al. ${ }^{17}$ They found that children's preferences for foods were largely a function of the television commercials they had been shown. When exposed to commercials for highly sugared foods, subjects in the study chose more sugared snacks. When exposed to pro-nutrition public service announcements (PSAs), however, they opted for more fruits, vegetables and other foods high in nutritional value.

The objective of this paper is to discuss the potential of regular advertising as a health-promotion tool and the theoretical perspectives required for the successful employment of this type of television content. A review of research on healthrelated portrayals in television advertising will be presented first. Next several strategies employing regular television fare as health education tools will be outlined. Finally, the theoretical and practical implications of the approach will be discussed.

\section{ADVERTISING AND HEALTH: REVIEW OF RESEARCH}

If the assumed link between health-related advertising on television and consumer preferences for health-related products is warranted, the question of which healthrelated products are advertised on television and in what way becomes imperative. That is, how can the health climate of television advertising be described? Unfortunately, content-analytic research on this issue is relatively scarce. ${ }^{18}$ Nevertheless, several interesting findings emerge from the studies that have been conducted.

For instance, in a content analysis of 20 hours of television, selected over a threeweek period, Wallack \& Dorfman ${ }^{19}$ found that approximately 31 per cent of all advertisements were (explicitly and implicitly) health related. Notably, most of these emphasised the nutritional value of the product. Similar results were obtained by Kaufman ${ }^{20}$ in a content analysis of the portrayal of nutrition on prime-time television (including other programme types besides commercials). The results from this research indicated that more than two-thirds of non-nutritious foods were represented in programme content other than television advertising, while 62 per cent of nutritious foods were represented in commercials. Based on these findings, Kaufman ${ }^{21}$ concluded that public health practitioners and other groups concerned with food messages on television 'may have been overly hasty in singling out advertising as the major culprit in the promotion of poor nutritional habits, and that greater attention ought to be paid to programme content as a source of food messages.'

The prevalence of advertising in the portrayal of health on television is not only found in the USA but has also been demonstrated in the Netherlands. ${ }^{22}$ Recent findings indicate that approximately 60 per cent of all health-related representations on 
television can be found in commercial airtime. ${ }^{23}$ This primarily involves advertising for products with an explicit health claim (eg high-fibre cereals with a postulated positive influence on digestion; vitamins and minerals added to regular food products; dental hygiene products). The results of these studies, then, do not support the often-heard contention that commercial air-time is filled with examples of health-compromising products and represents an anti-health orientation (eg Wallack ${ }^{24}$ ). This oftenstated criticism may be more attributable to a general skepticism towards advertising than the result of careful empirical scrutiny. ${ }^{25}$

These results point to an interesting possibility: using regular advertising messages as a new means of promoting health through the use of television. This approach may seem unorthodox but other (international) developments in the field of employing prototypical television programming may underscore its usefulness. In particular, two such initiatives will be discussed: the "media advocacy approach' and the 'entertainment education approach" ${ }^{\text {, }}$ before introducing a 'consumer behaviour approach' as means of using television advertising as a healthpromotion instrument.

\section{USING TELEVISION \\ PROGRAMMING AS A HEALTH- PROMOTION TOOL: THREE STRATEGIES}

\section{News programming as a health- promotion tool: The media advocacy approach}

Recently, several new techniques have been developed to increase the possibilities for public health institutions to gain access to the news media. These techniques have been termed the 'media advocacy approach' which has received a considerable amount of attention from scholars and health professionals alike. ${ }^{27,28}$ A fundamental assumption of media advocacy is that health and illness cannot just be considered an individual responsibility, but are codetermined by the broader social, political and economic structure of a community or society. One of the idiosyncratic features of the portrayal of health in television news, however, is the fact that health issues are often shown in a personalised context, suggesting an individual responsibility for the occurrence of health or illness. ${ }^{29}$ Modifying this conceptualisation of health issues so as to incorporate this broader societal perspective thus requires a more active and sometimes aggressive orientation of the public health community to the media. ${ }^{30}$ Media advocacy represents such a more active orientation, in that it is comprised of several techniques, derived from political and consumer interest groups, to actively gain access to the news media. Three techniques are used for this purpose: ${ }^{31}$

1 creative epidemiology

2 issue framing

3 gaining access to news media outlets.

With the aid of creative epidemiology the attention of the news media is drawn to a specific health issue by the use of (new) scientific evidence. It is creative in that it seeks to convey epidemiological information in ways that are congruent with the demands of the medium. As an example, consider a National Cancer Institute (NCI) video tape which explained that ' 1000 people quit smoking every day - by dying. That is equivalent to two fully loaded jumbo jets crashing every day, with no survivors'. ${ }^{32}$ By translating the number of smoking deaths into the passenger capacity of a jumbo jet, the NCI has reframed the issue of smoking deaths, which is in itself not interesting to news 
media, into a jet-crash issue, which has a higher news value, thus optimising the interest of the news media.

Apart from redefining health issues in terms more attractive to news programmers, issue framing further shapes the context in which health is covered in the news media. Not individuals but institutions, such as the Government and industry, become the focus of attention. For instance, media advocates have attacked the efforts of the tobacco industry to position itself as a sponsor of cultural events, by pointing out the restrictions on tobacco advertising, thus reframing such efforts by the tobacco industry as a way of circumventing legal regulations.

Finally, health educators may have more access to news media if they are able to present health issues as 'breaking news'. This, however, immediately posits a problem in the media advocacy approach as a result of the tendency of news programming to personalise health items, a perspective diametrically opposed to the ideological orientation of media advocates. Although promising, the media advocacy approach is still in its infancy, and thus lacks a comprehensive set of tools and principles.

\section{Television drama as a health- promotion tool: The entertainment education approach}

Apart from news, entertainment programming, such as soaps, feature films, series and situation comedies, are increasingly employed as a means to convey health-promotion messages. This development is internationally known as the 'entertainment education strategy'. $33-35$ In essence, this approach tries to incorporate health issues in entertainment programming in such a way as to foster healthy behaviour patterns on the screen, and, preferably, with the audience. ${ }^{36}$ In the past, this has led to such initiatives as the cooperation between health practitioners and scriptwriters to improve the portrayal of drinking in the situation comedy $M^{\star} A{ }^{\star}{ }^{\star} H .{ }^{37}$ More recently, the Dutch Heart Foundation has participated in the production of three episodes of a popular hospital drama series aired in the Netherlands. ${ }^{38}$ The entertainment education approach shares with media advocacy its techniques of gaining access to media organisations and professionals, but not necessarily its ideological orientation on the broad social and political context of health and illness.

Brown \& Walsh-Childers ${ }^{39}$ contend that the potential effectiveness of health messages embedded in entertainment programming is large and probably larger than that of the regular PSA, based on the following grounds:

- dramatic formats may be more capable than PSAs to attract and hold the audience's attention

- entertainment programming is more capable than PSAs to attract a larger, well defined audience

- because of its longer duration than PSAs, television drama has the opportunity to more persuasively present complex health issues.

Notwithstanding the supposedly large potential for television entertainment programming to affect health behaviour, there are several problems associated with this strategy. First, it is as yet unclear whether the portrayed health issues in such programming actually have the effects they are thought to have on knowledge, attitudes or behaviour. As yet, most evaluation studies reported have presented primarily correlational or qualitative data, so convincing evidence on the assumed causal link through experimental research is still lacking.

In addition, entertainment programming depends largely on advertising revenues, which decreases the likelihood that complex and controversial 
health issues will be featured in such programming.

Furthermore, the effectiveness of health portrayals in entertainment programming may, to a large extent, depend on the way they are presented. For instance, smoking and references to drinking are rather peripheral to the central storyline, and plots mostly do not evolve around such issues as eating or drinking habits, which often merely serve a social function. Thus it is questionable whether health issues that are not central to the story have the same impact as health issues that are. ${ }^{40}$

Finally, the portrayal of health issues in entertainment must conform to the 'conventions' used in this programme type. Thus, any health message must avoid being too 'blatant' or 'hard sell', because this may negatively affect audience share. ${ }^{41}$ In similar vein, not every health issue can be considered a suitable topic for insertion in entertainment programming. Alcohol and drug abuse have been incorporated successfully in television entertainment, probably because they possess an intrinsically 'dramatic' quality. ${ }^{42}$ Not all risky behaviours or illnesses share such dramatic features, however. Ailments such as arthritis or intestinal cancer may lend themselves less to an interesting and dramatic plot line.

\section{Television advertising as a health- promotion tool: The consumer behaviour approach}

In line with the approaches to employ regular television programming for healthpromotion purposes discussed earlier, advertising could perform a similar role. The potential of advertising to promote healthier lifestyles has been suggested by several authors (eg Calvert \& Cocking, ${ }^{43}$ Novelli ${ }^{44}$ ). Structuring this potential into a set of techniques and principles yields a strategy, termed the 'consumer behaviour approach', which can be defined as: 'a strategy aimed at modifying health- related aspects of consumer behaviour through commercial advertising in cooperation with manufacturers and marketers of health-related products and services'.

This definition implies two relationships that are in need of further clarification:

1 the relationship between health behaviour and consumer behaviour 2 the relationship between consumer behaviour and advertising effectiveness aimed at modification of health-related consumption patterns.

Both relationships will be discussed next.

\section{THE RELATIONSHIP BETWEEN HEALTH BEHAVIOUR AND CONSUMER BEHAVIOUR}

People's health is, to a large extent, a function of their lifestyle. This lifestyle, in turn, consists to a large degree of consumption-related behaviours, such as alcohol intake, smoking, or dietary habits. ${ }^{45,46}$ Slater \& Flora ${ }^{47}$ have emphasised this point by stating that consumer behaviour, as the result of targeted advertising, is often comprised of purchase decisions with explicit health consequences. These authors illustrate their assumptions by pointing out the health consequences of the foods consumers choose to buy or the decision to consume tobacco. In their view, even AIDS prevention has a consumer behaviour component since it involves the purchase and use of condoms. Slater \& Flora ${ }^{48}$ maintain that, in these cases, problems of health promotion become essentially the same as other marketing challenges.

Although health behaviour is, of course, intrinsically more complex than consumer behaviour, and can, therefore, not be equated with purchase and consumption patterns, ${ }^{49}$ viewing consumption and purchasing patterns as one of the causes of 
health and illness seems plausible and warrants more attention. A consumer behaviour perspective, then, offers an alternative perspective on health and health promotion using television (and other media). For one thing, it implies a shift in theorising from such well-known models as the health belief model, ${ }^{50,51}$ protection motivation theory ${ }^{52}$ and other expectancy value models to consumer behaviour theory. Although such health behaviour models have proven helpful in explaining specific behavioural interventions undertaken by individuals to improve their health, ${ }^{53}$ they share a fundamental problem with regard to the nature of their orientation on the individual, especially in a mass-mediated context.

An important assumption of these models is that people must be aware of some health risk and, as a minimum, be willing to contemplate behavioural change. Hence the models assume relatively high levels of involvement with the health issue, an assumption that may not always be warranted with regard to health behaviour, as Slater \& Flora ${ }^{54}$ have pointed out:

'such involvement is hardly a given and is not necessarily predictable even from actual and perceived risk. Perhaps the point we should keep in mind is that eating, smoking, drug and alcohol use, and sex are primarily health behaviours to only a few - notably health professionals while on the job. For most people, in most situations, the social and hedonic consequences of these behaviours are far more salient than the health consequences'.

Applying consumer behaviour theory to the field of public health and health promotion may be a viable alternative or supplement to the theoretical frameworks mentioned above, because it explicitly takes into account low-involvement consumer decision making and information processing. ${ }^{55}$ In addition, it may offer a framework for a better understanding of health behaviour from the consumers' point-of-view since it more closely mirrors their own perceptions of their health-related thoughts and actions.

Using consumer behaviour theories, the focus is not on a complete lifestyle to be changed, but on health-related or healthrelevant information processing, decision making, and purchase and consumption behaviour. Of course, lifestyle factors are of pivotal importance in explaining these behaviours, and thus require due attention. Other areas of research that may be fruitfully employed include advertising information processing models, ${ }^{56}$ research on environmental influences (eg culture, social class or reference groups), ${ }^{57}$ or individual differences (eg, personality variables, involvement, and motivation). ${ }^{58}$ Furthermore, diffusion of innovations models ${ }^{59}$ and theories on product and brand loyalty and switching ${ }^{60-61}$ may be helpful in explaining why consumers adopt or refuse to adopt health-related products and services.

\section{THE RELATIONSHIP BETWEEN CONSUMER BEHAVIOUR AND THE EFFECTIVENESS OF ADVERTISING AIMED AT MODIFYING HEALTH-RELATED CONSUMPTION PATTERNS}

The accumulated literature suggests that mass media (especially television) may be effective in creating awareness, knowledge gain, belief change, attitude change and sometimes behavioural intentions with regard to health-related issues. The potential of television to directly modify actual (health) behaviour is, however, rather modest. ${ }^{62-63}$ This implies that the chances of effectively changing complex health behaviours, like a complete lifestyle, are rather slim. Winett ${ }^{64}$ has therefore argued that television is a particularly suitable medium for changing simple (but not trivial) behaviours. Hence relatively simple behaviours such as purchase choices, 
may, under certain conditions, be changed as a result of television advertising. ${ }^{65}$ This makes the consumer behaviour approach probably more in accordance with the features of television, its requirements, and its possibilities as a health-promotion instrument than many of the more complex health behaviour models. Thus television advertising for health-related products may positively or negatively affect consumer choices, and, as a result, impact on the health behaviour of the consumer. This may create a potential to use advertising for health-promotion purposes. It starts with the assumption that certain kinds of health education do not function very differently from other marketing communication efforts, and that the same type of communication can be used.

Before a public health organisation decides on (commercial) advertising as a communication tool, however, it must thoroughly analyse and segment the target audience on such dimensions as involvement with a product class, purchasing habits, brand loyalty and prior product knowledge, to determine whether switching a product or brand to a healthier alternative is a realistic communication goal. Because this approach is embedded in the normal consumption patterns of the audience, it may prove to be especially effective when involvement with a health issue is low.

\section{COMMERCIAL ADVERTISING AND HEALTH PROMOTION: PRACTICAL IMPLICATIONS}

One way of strategically disseminating health messages through commercial advertising is by cooperation between a public health organisation and a manufacturer of health-related products. Several authors have suggested this possibility or have conducted research into its effectiveness. ${ }^{66-72}$
An example of such a cooperation that has received a large amount of attention is the one between Kellogg and the US NCI. In 1984, Kellogg mounted a new media campaign for its All-Bran cereal, both by means of print advertisements and television commercials. The advertising campaign focused on the claim that the product is high in fibre. The NCI endorsed the product by pointing out the health benefits of a high fibre/low fat diet in reducing the risk of certain types of cancer. Several studies have examined the effectiveness of this campaign. ${ }^{73-75}$ The research evaluating the campaign ${ }^{76}$ showed a significant increase in the percentage of consumers that were convinced of the merits of a high-fibre diet as a means of cancer prevention. In addition, they acted accordingly by increasing their fibre consumption (compared with the period before the start of the campaign). ${ }^{77}$

An analysis of purchase data further revealed that the campaign had a positive effect on All-Bran's market share.

Moreover, consumption of other brands of high-fibre cereals had also increased, ${ }^{78}$ which indicates that the campaign resulted not only in brand switching (switching within product category) but even in product switching (switching between product categories) from low- to highfibre cereals. ${ }^{79}$

Other research concerning the campaign focused on the effects on attitudes towards the NCI and the advertising message itself. ${ }^{80}$ Results from this (experimental) study indicated that a non-profit source (such as the NCI) had a higher perceived credibility than a profit source (like Kellogg). Furthermore, the joint appearance of both the non-profit and the profit source (as in the actual campaign) did not result in perceived loss of credibility compared with the non-profit source alone. Nevertheless, source credibility had no impact on message acceptance. ${ }^{81}$ Notwithstanding this last 
result, many authors have propagated the collaboration between public health practitioners and marketers. Novelli, ${ }^{82}$ for example, has argued that the concept of linking commercial products with public sector endorsement is useful for both parties. That is, commercial organisations are attracted by the authority and credibility that a government agency, a major non-profit voluntary organisation or a professional medical organisation can add to their brands. Furthermore, public health organisations are naturally interested in the expanded communications reach, funding and marketing knowledge and skills that companies can bring. ${ }^{83-84}$

To summarise, the studies mentioned above suggest that the consumer behaviour approach may be an effective strategy to change a relatively simple and concrete behaviour through commercial television advertising. As such it may be regarded as a promising additional approach for professional health-promotion purposes (next to such approaches as the media advocacy approach and the entertainment education strategy). Furthermore, it may prove to be a viable strategy to reach populations with specific health risks. Research has indicated that the lower socio-economic strata run greater health risks, suffer more from chronic diseases and are especially hard to reach, inform and persuade using standard health campaign material. ${ }^{85}$ This audience segment watches more television and does so more frequently than any other demographic group, however. ${ }^{86}$ Furthermore, research by Mittal ${ }^{87}$ indicated that, although the general public tends to have a rather negative attitude towards television advertising, and irritation is becoming an increasing problem for advertisers, ${ }^{88}$ less-educated viewers are significantly less skeptical and more tolerant of television commercials than other strata. This would imply that television advertising (and possibly educational entertainment programming) may be a relatively more effective healthpromotion tool among this group than regular public health campaigns.

Moreover, the consumer behaviour approach may be a viable healthpromotion tool for those public health organisations for which other forms of (television) communication are difficult to employ (ie health organisations that lack resources to develop effective campaign materials such as PSAs or buy advertising time on television). As Novelli ${ }^{89}$ has pointed out, in such cases, joining forces with a commercial advertiser may not only provide the ability to reach a large audience, but may also provide additional funding for future (or parallel) campaigns. This could also create synergistic effects since the campaign material may focus on the broader lifestyle-related context of the target health behaviour, while the advertising campaign may reinforce this message by giving an example of how to translate this broader message into an explicit example of concrete and simple behaviour. Cross-reference to the various communication efforts may further strengthen the association between both types of health messages.

Also, health educators that focus on health issues that lack an intrinsic 'dramatic quality' or cannot be framed in a news format cannot consider entertainment education or media advocacy approaches viable options to use conventional television programming for healthpromotion purposes. In such cases, advertising could prove to be an effective way to disseminate health messages to a target audience. Additionally, contrary to PSAs, commercial advertising can be scheduled in more effective time slots (for example prime-time), or placed in an environment which is favourable to the message. ${ }^{90}$ Finally, cooperation between a health organisation and a commercial advertiser can prove beneficial because it 
allows both parties to exchange communication knowledge and skills.

\section{DISCUSSION}

The consumer behaviour approach may be regarded as a promising framework for health-promotion purposes. The approach is in accordance with international developments to employ conventional television programming as a health education tool. The initiatives that have already emerged in the field have certainly shown promising results. Theoretical and empirical notions from the consumer behaviour literature could provide the field of health education and promotion with a fruitful and rich reservoir based on their congruence with the perceptions of consumers of their own health.

Furthermore, with its emphasis on relatively simple types of behaviour, the consumer behaviour approach might increase the chances of success of health-promotion efforts targeted at those segments that currently have the highest health risks.

Still, there is a need for clear guidelines to professionalise the relationship between health communicators and advertisers, to enable them to work together in achieving better health and better profits. Perhaps the notions presented in this paper could bring both parties a little closer together.

\section{References}

1 Gerbner, G., Morgan, M. and Signorielli, N. (1982) 'Programming health portrayals: What viewers see, say, and do', in D. Pearl, L. Bouthilet and J. Lazar (eds), Television and Behavior: Ten Years of Scientific Progress and Implication for the Eighties, Vol II, Technical reviews. US Department of Health and Human Services, Rockville, Maryland.

2 Wallack, L. and Dorfman, L. (1992) 'Health messages on television commercials', American Journal of Health Promotion, 6, 190-196.

3 Yankelovich, Skelly and White, Inc. (1979) The General Mills American Family Report: 1978-1979: Family Ties in an Era of Stress. General Mills, Minneapolis.

4 O'Keefe, G.J., Boyd, H.H. and Brown, M.R. (1998) 'Who learns preventive health care information from where: Cross-channel and repertoire comparisons', Health Communication, 10, 25-36.
5 Fishbein, M., Hall-Jamieson, K., Zimmer, E., von Haeften, I. and Nabi, R. (2002) 'Avoiding the boomerang: Testing the relative effectiveness of antidrug public service announcements before a national campaign', American Journal of Public Health, 92, 238-245.

6 Warner, K.E. (1987) 'Television and health education: Stay tuned', American Journal of Public Health, 77, 140142.

7 Glanz, K., Marcus Lewis, F. and Rimer, B.K. (1990) 'The scope of health education: Parameters of a maturing field', in K. Glanz, F. Marcus Lewis and B.K. Rimer (eds), Health Behavior and Health Education. Jossey-Bass, San Francisco, California.

8 Atkin, C. and Arkin, E.B. (1990) 'Issues and initiatives in communicating health information', in C. Atkin and L. Wallack (eds), Mass Communication and Public Health: Complexities and Conflicts. Sage, Beverly Hills, California.

9 Donohew, L. (1990) 'Public health campaigns: Individual message strategies and a model', in E.B. Ray and L. Donohew (eds), Communication and Health: Systems and Applications. Erlbaum, Hillsdale, New Jersey, 136.

10 Wallack, L. (1990) 'Improving health promotion: Media advocacy and social marketing approaches', in Atkin and L. Wallack (eds), Mass Communication and Public Health: Complexities and Conflicts. Sage, Beverly Hills, California.

11 Winett, R.A. (1987) 'Prosocial television for community problems: Framework, effective methods. and regulatory barriers', Prevention in Human Services, 5, 117-160.

12 Gerbner, G., Morgan, M. and Signorielli, N. (1982) op. cit.

13 Andrews, J.C., Burton, S. and Netenmeyer, R.G. (2000) 'Are some comparative nutrition claims misleading? The role of nutrition knowledge, ad claim type and disclosure conditions', Journal of Advertising, 29, 29-42.

14 Kardes, F.R. (2002) Consumer Behavior and Managerial Decision Making, 2nd edn. Pearson, Upper Saddle River, New Jersey.

15 Schiffman, L.G. and Kanuk, L.L. (2000) Consumer Behavior, 7th edn. Prentice Hall, Upper Saddle River, New Jersey.

16 Solomon, D.S. (1982) 'Health Campaigns on Television', in D. Pearl, L. Bouthilet and J. Lazar (eds), Television and Behavior: Ten Years of Scientific Progress and Implication for the Eighties, Vol II, Technical reviews. US Department of Health and Human Services, Rockville, Maryland.

17 Goldberg, M.E., Gorn, G. and Gibson, W. (1978) 'TV messages for snack and breakfast foods: Do they influence children's preferences?', Journal of Consumer Research, 5, 73-81.

18 Bogart,L. (1988) 'The multiple meanings of television advertising', Society, 25, 76-80.

19 Wallack, L. and Dorfman, L. (1992) op. cit.

20 Kaufman, L. (1980) 'Prime time nutrition', Journal of Communication, 30, 37-46.

21 Ibid., 41. 
22 Fennis, B.M. and Bakker, A.B. (2001) " "Stay tunedWe will be back right after these messages" Need to evaluate moderates the transfer of irritation in advertising', Journal of Advertising, 30, 15-25.

23 Ibid.

24 Wallack, L. (1983) 'Mass media campaigns in a hostile environment: Advertising as anti-health education', Journal of Alcohol and Drug Education, 28, 51-63.

25 Novelli, W. (1990) 'Controversies in advertising of health-related products', in C. Atkin and L. Wallack (eds), Mass Communication and Public Health: Complexities and Conflicts. Sage, Beverly Hills, California

26 Brown, J.D. and Walsh-Childers, K. (1994) 'Effects of media on personal and public health', in J. Bryant and D. Zillmann (eds), Media Effects: Advances in Theory and Research. Erlbaum, Hillsdale, New Jersey.

27 Ibid.

28 Wallack, L. (1990) op. cit.

29 Turow, J. and Coe, L. (1985) 'Curing television's ills: The portrayal of health care', Journal of Communication, 35, 36-51.

30 Wallack, L. (1990) op. cit.

31 Ibid.

32 Ibid.

33 Bouman, M. (1999) The Turtle and the Peacock: The Entertainment-Education Strategy on Television. Wageningen University, dissertation.

34 Breed, W. and DeFoe, J. (1982) 'Effecting media change: The role of cooperative consultation on media topics', Journal of Communication, 32, 88-99.

35 Montgomery, K.C. (1990) 'Promoting health through entertainment television', in C. Atkin and L. Wallack (eds), Mass Communication and Public Health: Complexities and Conflicts. Sage, Beverly Hills, California.

36 Brown, J.D. and Walsh-Childers, K. (1994) op. cit.

37 Breed, W. and DeFoe, J. (1982) op. cit.

38 Bouman, M. (1999) op. cit.

39 Brown, J.D. and Walsh-Childers, K. (1994) op. cit.

40 Signorielli, N. (1990) 'Television and health: Images and impact', in C. Atkin and L. Wallack (eds), Mass Communication and Public Health: Complexities and Conflicts. Sage, Beverly Hills, California.

41 Atkin, C. and Arkin, E.B. (1990) op. cit.

42 Montgomery, K.C. (1990) op. cit.

43 Calvert, S.L. and Cocking, R.R. (1992) 'Health promotion through mass media', Journal of Applied Developmental Psychology, 13, 143-149.

44 Novelli, W. (1990) op. cit

45 Hirschman, E.C. (1991) 'Secular mortality and the dark side of consumer behavior: Or how semiotics saved my life', Advances in Consumer Research, 18, 1-4.

46 Story, M. (1990) 'Study group report on the impact of television on adolescent nutritional status', Journal of Adolescent Health Care, 11, 82-85.

47 Slater, M. and Flora, J. (1994) 'Is health behavior consumer behavior? Health behavior determinants, audience segmentation, and designing media health campaigns', in E.M. Clark, T.C. Brock and D.W. Stewart (eds), Attention, Attitude, and Affect in Response to Advertising. Erlbaum, Hillsdale, New Jersey.
48 Ibid.

49 Ibid.

50 Janz, N.K. and Becker, M.H. (1984) 'The health-belief model: A decade later', Health Education Quarterly, 11, $1-47$.

51 Rutter, D. and Quine, L. (2002) 'Social cognition models and changing health behaviours', in D. Rutter and L. Quine (eds), Changing Health Behaviour: Intervention and Research with Social Cognition Models. Open University Press, Buckingham, UK. 1-27.

52 Rogers, R.W. and Mewborn, C.R. (1976) 'Fear appeals and attitude change: Effects of noxiousness, probability of occurrence, and the efficacy of coping responses', Journal of Personality and Social Psychology, 34, 54-61.

53 Witte, K., Stokols, D., Ituarte, P. and Schneider, M. (1993) 'Testing the health belief model to promote bicycle safety helmets', Communication Research, 20, 564-586.

54 Slater, M. and Flora, J. (1994) op. cit., 275-276.

55 Kardes, F.R. (2002) op. cit.

56 MacInnis, D.J. and Jaworski, B.J. (1989) 'Information processing from advertisements: Toward an integrative framework', Journal of Marketing, 53, 1-23.

57 Schiffman, L.G. and Kanuk, L.L. (2000) op. cit.

58 Kardes, F.R. (2002) op. cit.

59 Rogers, E.M. (1983) Diffusion of Innovations, 3rd edn. Free Press, New York.

60 Ehrenberg, A.S.C. (1988) Repeat-buying: Facts, Theory and Applications. Charles Griffin, London.

61 Schultz, D.E. and Bailey, S. (2000) 'Customer/brand loyalty in an interactive marketplace', Journal of Advertising Research, May/June, 41-52.

62 McQuail, D. (1994) Mass Communication Theory: An Introduction, 3rd edn. Sage, Beverly Hills, California.

63 Stroebe, W. and Stroebe, M.S. (1995) Social Psychology and Health, Open University Press, Buckingham, UK.

64 Winett, R.A. (1987) op. cit.

65 Goldberg, M.E., Gorn, G. and Gibson, W. (1978) op. cit.

66 Atkin, C. and Arkin, E.B. (1990) op. cit.

67 Brown, J.D. and Walsh-Childers, K. (1994) op. cit.

68 Novelli, W. (1990) op. cit.

69 Freimuth, V.S., Hammond, S.L. and Stein, J.A. (1988) 'Health advertising: Prevention for profit', American Journal of Public Health, 78, 557-561.

70 Hammond, S.L. (1987) 'Health advertising: The credibility of organizational sources', in M.L. McLaughlin (ed.), Communication Yearbook, Vol. 10. Sage, Beverly Hills, California.

71 Levy, A.S. and Stokes, R.C. (1987) 'Effects of a health promotion advertising campaign on sales of ready-toeat cereals', Public Health Reports, 102, 398-403.

72 Warner, K.E. (1987) op. cit.

73 Freimuth, V.S., Hammond, S.L. and Stein, J.A. (1988) op. cit.

74 Hammond, S.L. (1987) op. cit.

75 Levy, A.S. and Stokes, R.C. (1987) op. cit.

76 Freimuth, V.S., Hammond, S.L. and Stein, J.A. (1988) op. cit.

77 Ibid.

78 Levy, A.S. and Stokes, R.C. (1987) op. cit. 
79 Ibid.

80 Hammond, S.L. (1987) op. cit.

81 Ibid.

82 Novelli, W. (1990) op. cit.

83 Brown, J.D. and Walsh-Childers, K. (1994) op. cit.

84 Warner, K.E. (1987) op. cit

85 Freimuth, V.S. (1990) 'The chronically uninformed: Closing the knowledge gap in health', in E.B. Ray and L. Donohew (eds), Communication and Health: Systems and Applications. Erlbaum, Hillsdale, New Jersey.
86 Jason-Beeck, M. and Sobal, J. (1980) 'The social world of heavy television viewers', Journal of Broadcasting, 24, 5-11.

87 Mittal, B. (1994) 'Public assessment of TV-advertising: Faint praise and harsh criticism', Journal of Advertising Research, Jan/Feb, 35-53.

88 Fennis, B.M. (1999) Health on Television: Studies on the Content and Effects of Mass Media Messages. Utrecht University, dissertation.

89 Novelli, W. (1990) op. cit.

90 Atkin, C. and Arkin, E.B. (1990) op. cit. 
Copyright $\odot 2003$ EBSCO Publishing 